\title{
One Health workers: innovations in early detection of human, animal, and plant disease outbreaks
}

\author{
Michael Wilkes', Sophia Papageorgiou², Tae Youn Kim³, Loinda Baldrias', Edna Aguilar, Terra Kelly², Michael Tee ${ }^{5}$ \\ ${ }^{1}$ School of Medicine, University of California, Davis, California, USA, 2 One Health Institute, School of Veterinary Medicine, University of California, \\ Davis, California, USA, ${ }^{3}$ School of Nursing and Health, University of California, Davis, California, USA, ${ }^{4}$ University of the Philippines, Los Banos, \\ Laguna, Philippines, ${ }^{5}$ School of Medicine, University of the Philippines, Manila, Philippines \\ Keywords: disease outbreaks, one health, global health \\ https://doi.org/10.29392/joghr.3.e2019093
}

\section{Journal of Global Health Reports}

Vol. 3, 2019

\begin{abstract}
The majority (60\%) of human pathogens are zoonotic and $75 \%$ of emerging zoonotic pathogens are from wildlife species (eg, Ebola, Zika). In addition, vector, water, and food-borne diseases greatly impact people, livestock, and agriculture and result in adverse effects on local, national, and global economies. Continuous monitoring and surveillance of newly emerging diseases and pandemic outbreaks is a critical component in One Health $(\mathrm{OH})$ which is the term representing the collaboration of multiple disciplines working to achieve optimal health for people, animals, plants/crops, and the environment. For decades a group of minimally trained local workers -community health workers - (CHWs) have functioned at the interface between community members and whatever health care system existed within a country. Today, around the world CHWs have become the bedrock and frontline health care providers as they deliver or monitor human treatments, engage in the detection of common illness, and offer preventive care. In these same communities there is often severely limited access to veterinary health services which has a negative impact on livestock production with implications for food security, and has led to the inappropriate and indiscriminate use of antibiotics. In rural areas poor field maintenance and common agricultural health problems results in the death or decreased crop production of important food sources. Inappropriate use of pesticides and other products that are toxic to animals and humans often enter the soil or water supply through misuse. This lack of health integration across human, animal, plant, and environmental health sectors in an ever-shrinking world begs for a shift in health services and the creation of a community based One Health Worker.
\end{abstract}

In many regions around the world people are living longer and healthier lives. However, environmental pressures, climate change, population growth, and food security issues have created health problems that require a multidisciplinary One Health $(\mathrm{OH})$ approach to finding solutions. One Health is the term that refers to the collaboration of multiple disciplines working locally, nationally, and globally to attain optimal health for people, animals, plants, and the environment. ${ }^{1}$ In this paper we outline one communitybased approach to monitor and improve early detection of $\mathrm{OH}$ problems, to build human health capacity to solve those problems, address animal and plant health problems, and to harness the power of technology while also serving to identify emerging and re-emerging disease at an earlier period when early intervention will prove more effective.

We are constantly reminded of emerging and re-emerging zoonoses (Ebola virus disease, Middle East Respiratory Syndrome (MERS), Influenza A), and diseases in plant species (Taro leaf blight, wheat head blight, potato blight) that show how vulnerable plants and life sustaining agriculture are to disease. ${ }^{2-6}$ The majority $(75 \%)$ of new and re-emerging human pathogens are zoonotic emerging from wild animal species. ${ }^{1,7}$ As the human population increases, people are forced to live in closer proximity to wild and domestic animals which forces the sharing of limited food and water supplies increasing exposure to new pathogens. ${ }^{8}$ To this, add the desire for generating new reveue by low-middle income countries through ecotourism which brings humans and animals into closer contact leading to the spead of illness, sometimes lethal, back and forth between humans and vulnerable wildlife. A recent example of this is the spread of human viral respiratory disease to vulnerable mountain gorillas (Gorilla beringei beringei). ${ }^{9}$

Infectious diseases are not the only $\mathrm{OH}$ concern affecting human, animal, and plant health. ${ }^{9}$ Waste and toxins dumped in, or near, water contaminate streams, rivers, and lakes affecting entire communities of crops, animals and people. ${ }^{10,11}$ Landscape alterations such as deforestation or algae blooms impact land quality, natural animal habitat, and erosion in areas. Beyond landscape changes, there are pressures to increase agricultural production, global warming with resultant changes in weather that decrease freshwater supplies, and changing microbial patterns that result in a deterioration of natural resources and the reduction in many of the protective ecological functions that maintain healthy ecosystems and benefit human, animal, and plant 
communities. ${ }^{12}$ Moving forward, a focus on promoting health depends on expanding from a uniquely human centric perspective to a broader $\mathrm{OH}$ perspective with attention on the interdependence between humans, animals, plants, and the environment.

There are key advantages of an integrated $\mathrm{OH}$ systems approach to reducing disease and managing ecosystems including:

- engaging in the early and rapid detection of health threats;

- collecting data to promote an integrated disease surveillance, prevention, and response system;

- improving education and communication among professionals focused on human, animal, plant, and environmental issues to allow for earlier intervention;

- exposing and integrating students engaged in professional education to concepts related to $\mathrm{OH}$ that facilitates inter-professional collaboration around discovery, innovation, and research;

- developing policy focused on upstream drivers of disease emergence including land use and landscape alterations, water access and cleanliness, migration, and climatic shifts; and

- strengthening the economy by improving long term impacts on food safety, security, and

1. productivity. $^{13-16}$

\section{COMMUNITY HEALTH WORKERS}

For decades, under various names (eg, Chinese barefoot doctors and Russian feldshers) and job descriptions, a group of minimally trained local workers have sought to function at the interface between community members and whatever health care system exists within a country. ${ }^{17,18}$ Today, around the world, in countries such as Rwanda, Ethiopia, Sri Lanka, and South Africa, community health workers (CHWs) have become the bedrock and frontline health care providers as they deliver or monitor treatments, engage in the detection of common illness such as malaria and HIV, or offer preventive care through immunization, and maternal and child health. CHWs could be the peripheral nervous system of a nation transmitting local information to a central processing center where executive decisions can be made, and early disease patterns and epidemics identified. At a central level the decisions made are carried back to the end organ - the community - in the form of treatments or early interventions. Today, these frontline CHWs function in their communities to provide limited primary preventive and curative services directed at humans but as a result of their job description little attention is given to the animal, plant, and environmental health interfaces.

CHWs have great potential to improve the health of a community but their job description needs to be broadened without significantly changing their mission. Despite decades of providing services at the frontlines, CHWs often still function in a grey area of health care delivery and are often under-trained with little support. This is where technology can be enabling. CHWs need additional training and supervision, access to high-quality health information, and technology such as mobile devices capable of providing just-in-time information and improved communication with higher level providers. ${ }^{19}$

Rural community's limited access to veterinary health services has not only had a negative impact on livestock production with implications for food security, but has led to the inappropriate and indiscriminate use of antibiotics given to animals by lay people struggling to maintain their animals' health 20 and increase productivity. Not long after the value of CHWs was realized by the human health community, non-governmental organizations (NGOs) began training teams of Community Veterinary Workers (CVWs) to deliver basic treatment to animals (eg, vaccinations, anthelminthics) in remote rural areas. ${ }^{21}$

In those same isolated rural areas, there have also been attempts to provide small commercial and family farmers with agricultural advice, often through agricultural extension programs aimed at increasing yield production and reducing the use of harmful pesticides. ${ }^{22}$ Poor field maintenance and failure to recognize common agricultural health problems results in the death or decreased crop production of important food sources. ${ }^{23}$ Inappropriate use of pesticides and other products that are toxic to animals and humans often enter the soil or water supply through misuse. ${ }^{24}$ This lack of health integration across human, animal, plant, and environmental health sectors in an ever-shrinking world with landscape degradation and decreased access to clean water begs for a shift in health services.

\section{INNOVATIONS}

\section{A NEW PARADIGM FOR COMMUNITY HEALTH WORKERS}

Studies suggest enormous health benefits are derived from community workers. ${ }^{25,26}$ But, what if the CHWs job shifted from an entirely human focus to one with a one health focus to provide support across all four domains, human, animal, plant/crop, and the environment, to enhance health in the broadest sense ${ }^{27}$ ? What if rather than being trained to deliver advice and treatment based on their own knowledge and memory recall, CHWs could rely on technology to provide evidence-based recommendations around human, animal and environmental/crop syndromes while also collecting and recording data that could be forwarded to referral centers, as well as to district or national disease monitoring centers for early outbreak detection and pathogen identification?

Globally, the World Health Organization (WHO) estimates that more than 400 million people lack access to health providers and basic healthcare services. ${ }^{28}$ This gap is far larger when considering access to veterinary health and agricultural services. To meet this challenge our international team has developed a human workforce innovation - a new model of CHWs termed a "One Health Worker" (OHW) with two objectives - 1) addressing basic human, animal, crop/plant, and environmental health issues at the community level, and 2) early identification of pandemic disease threats. ${ }^{29-31}$ The goals for carefully trained and supervised OHWs (Figure 1) are to 1) perform syndromic surveillance for human, animal, and plant diseases, 2) use technology assisted mobile devices to provide health advice and education at the household level, 3) use this same tech- 
nology to collect and aggregate health data (animal, human, plant, environment) across regions to enable rapid detection of emerging diseases, and 4) facilitate the timely and appropriate referral to more advanced health professionals (human, animal, and plant) by providing an electronic record of all encounters.

\section{INNOVATIONS IN ONE HEALTH}

In most rural areas in low and middle-income countries the detection of, and response to, important diseases is slow and fraught with problems related to 1) collecting accurate data over wide geographic areas, 2) poor inter- and intraprofessional communication, and 3) rapid aggregation of data into a useable format to show disease trends. The expanded use of mobile technology is a worldwide phenomenon both in and outside of healthcare. As availability of wireless access has improved mobile technology is being used to assist CHWs particularly related to delivering prenatal care and family planning services. ${ }^{32}$ Furthermore, mobile devices and a variety of software are accepted and valued by both CHWs and the public. Mobile health tools can provide rapid collection of data, collection of media rich data (videos, photos, audio, geo-positions), real time consultations, and professional supervision.

mHealth tools have been shown to guide health care workers through the collection of surveillance data and the dissemination of "just in time" prompts and recommendations, but this technology has not been utilized to provide data on diseases, or adverse health events, affecting human, animals, crops, and local environmental issues. ${ }^{33}$ Advantages of technology for providing "just-in-time" health guidance to OHWs include timelier care, a higher quality of evidence-based care, and more rapid resolution of problems including appropriate referrals. There are also enormous benefits in being able to geo-tag data through the global positioning system (GPS) to allow for the collection and surveillance and monitoring of incoming data related to humans, animals, and crops at the family and community level. We have developed a training course and an interactive mobile application (APP) with push and pull technology.

Our mHealth smart device APP is developed around a pictorially driven menu protocol with simple pattern recognition and does not depend on thousands of hours of experience or classroom teaching to build expertise that is needed for high level critical thinking. Rather, our APP distills expertise into manageable patterns such that relatively inexperienced workers with only a secondary education can use these tools to identify common and important syndromes, and notify trained professionals (eg, municipal level health, animal, and agriculture professionals) as needed. The APP menu is designed to be visually driven by photos, animations, and diagrams to aide in navigation. This tool can run either offline to circumvent problems with reliable internet access, or on a nation's wireless telephone network to transfer data to a cloud server. The APP's PULL technology collects geo-linked data from the OHWs input (via their APP) on $\mathrm{OH}$ problems.

Behind the scenes a web-based tool aggregates data input from all the OHWs and PUSHes that data out such that

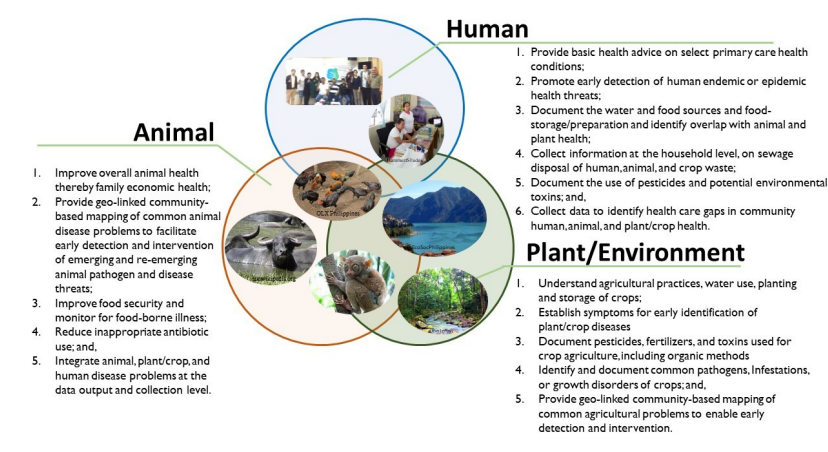

\section{Figure 1}

$\mathrm{OH}$ goals to improve human, animal, and plant/environment health in communities. $\mathrm{OH}$ - One Health.

it can be combined with climate information (eg, temperature, rain fall) or other data, to create a geo-linked dashboard of syndromes that may indicate potential outbreaks. Each morning the dashboard displays problem areas for evaluation by municipal, regional, or national level agency experts, for possible early intervention and follow-up. For complex problems or serious outbreak concerns, messages, photos, and history of the problem can be sent by supervising nurses to the respective human, animal, or plant experts who can opt to advise the OHW via text message or pay a visit to the family in person. The advantage of our innovative system is that it can: 1) aid in providing surveillance coverage to a large area using existing human resources; 2) be easily scaled; and 3) includes numerous human, animal, and plant/crop diseases and management issues that impact the community and nation.

\section{CONCEPTUAL MODEL}

The concept of holistically linking human, animal, environment, and plant/agricultural health issues is not new. As shown in Figure 2, there are multiple factors that impact one health at the animal/ecological/human level across the nation. Data is needed from a variety of sources to effectively and strategically determine interconnections across the domains, reduce disease burden and inform policy changes including early intervention of emerging disease threats. There is a vital role that can be played by OHWs as they engage in problem identification at the local level (Figure 2). Each community in which OHWs function has its own demographics and unique social and cultural norms that influence the acceptance of the OHW. Each community exists with its unique environmental issues including weather and water source concerns and may also include major employers/industries or recreational activities. It is this community that the OHW, assisted by technological tools, will be trained in communication skills, technology application, approaches to education and behavior change, and basic health knowledge so that they can provide grassroots linkages between the community and the formal human health care, animal, and agricultural management systems through collection and dissemination of health data. Each OHW will follow evidence-based protocols and report to advanced practitioners such as nurses, physicians, vet- 
erinarians, and agricultural officers. Easily interpreted data will then be aggregated and disseminated to regional and national experts who will engage in decision making to promote the health of the public and achieve a set of measurable outcomes.

\section{TECHNOLOGY-ENABLED ONE HEALTH SURVEILLENCE IN THE PHILIPPINES}

\section{PHILIPPINES: MOVING FROM CHW TO OHW}

The Philippine government, like many others, is faced with important health challenges including the shortage of welltrained, motivated, and equitably deployed health workers, particularly in geographically isolated rural regions where $56 \%$ of the population resides. ${ }^{34}$ Demands for living space, clean water, food security, animal health, crop productivity, and clean, inexpensive energy pose enormous social, political, and economic challenges that have significant impacts on human health and well-being. ${ }^{35}$ In this lower middleincome country with greater than 103 million people, 4\% of the gross domestic product is allocated for health care, making equitable provision of health care a challenge. ${ }^{36}$ Large regions of the country have limited access to primary care and even fewer have access to expertise for animal or plant health. Further, rural populations often have no reliable form of transportation to access healthcare often located many kilometers away. There are other roadblocks, such as economic feasibility or infrastructure support (e.g. electricity, water systems), to building and staffing clinics or hospitals in rural areas. In terms of health indicators, the Philippines lags behind other Asian countries including India, Malaysia, Thailand, Vietnam, and Sri Lanka. ${ }^{37}$

In the Philippines the community clinic-based health worker is termed a "barangay (village) health worker" (BHWs). BHWs are local community members who take an 80-hour course focused on a small number of human health issues. They typically work within the community clinics except when they engage in specific community outreach programs such as village-wide immunization programs. Currently, BHWs are involved in promoting immunization, educating women about pre- and postnatal care, and in other programmatic efforts raising community awareness around child and maternal health. In the Philippines, BHWs have had mixed results, but overall, they show a moderate level of competence with a clear need and a strong desire for additional training and mentoring. 38

Both in the Philippines, and globally, governments and NGOs have developed training programs that typically exclude concerns that are relevant to $\mathrm{OH}$, including issues related to environmental pollution, toxins, zoonotic diseases, animal or plant health, water quality, and food safety and security. Lack of essential $\mathrm{OH}$ services in remote areas can lead to inadequate human and animal vaccination programs, decreased herd health and productivity, decreased crop production, and missed opportunities for the early intervention of disease outbreaks.

New methods of health improvement require a less reductionist and siloed approach and a more efficient and integrated approach that goes beyond focusing on one disease, one region, or even one species. The complexity of

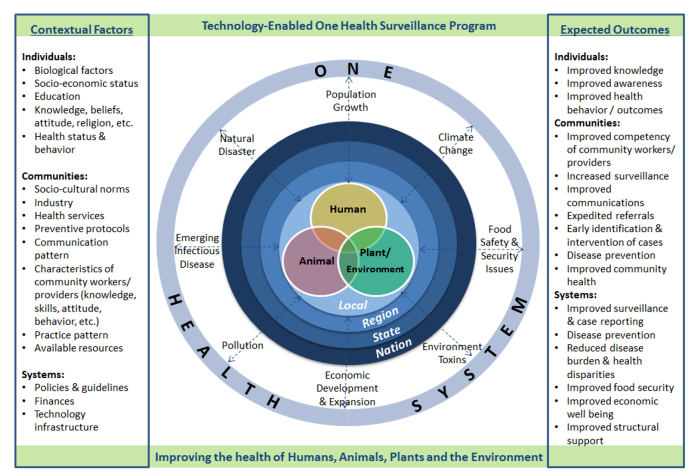

\section{Figure 2}

Conceptual Model for a Technology-Enabled One Health Surveillance Program.

current health problems requires interdisciplinary expertise and a genuine cooperation of numerous governmental and nongovernmental agencies capable of understanding, monitoring, and engaging in collaboration to protect human, animal, and environmental health. ${ }^{39}$ No one scientific discipline, NGO, or governmental organization has the expertise or resources to address the emerging or reemerging threats to health. By breaking down barriers between disciplines and governmental agencies the Philippines government seeks to develop forward-looking solutions to meet its health challenges. Our strategy to address the health concerns of humans, animals, and plants/crops in rural areas is to develop a newly aligned community health workforce - a One Health Worker - who will work across the domains and provide these workers with technological resources.

\section{IMPLEMENTATION OF A ONE HEALTH SURVEILLANCE PROGRAM}

The Philippines government seeks to improve health through early detection, intervention, and monitoring of $\mathrm{OH}$ problems. One important step is the development of a OHW workforce guided by the training and technological resources based on internationally accepted evidence-based recommendations.

- On the animal front, OHWs will use their mobile APP to collect data that will be useful to understand the community's relationship with animals, approaches used in animal husbandry, management of animals used for food consumption, common animal illness and treatments including successes and failures, and methods of slaughter for food preparation and storage. The mHealth technology will provide algorithms for common animal problems, suggestions for interventions, and allow timely access to experts for concerns that are not routine or when suggested interventions have failed.

- Many rural households have gardens or reside close to cultivated crops in the Philippines. In 2017, approximately $25 \%$ of the Filipinos were employed in plant agriculture that includes rice, coconuts, banana (abaca), corn, rubber, and many other fruits and vegetables. ${ }^{40}$ In the Philippines cultivation of these crops often demands fertilizer and pesticide use to manage 
pests and optimize crop yields. Even the use of organic fertilizers may contaminate food sources with zoonotic or environmental pathogens or contribute to leaching of pesticides and/or toxins into the environment. ${ }^{10}$ The OHW will identify patterns of specific pesticide or fertilizer use and help in the early detection of plant/crop diseases and/or crop failures. With the guidance of their mobile app, and access to agricultural expertise at the academic or district level, community-based OHWs will provide monitoring and advice for plants and crops.

- On the human side of the $\mathrm{OH}$ triad, OHWs seek to narrow health care disparities as they engage in regular house to house surveillance for acute illness and provide health advice/education. OHWs will provide just-in-time health advice using the evidence-based mHealth device that guides them through algorithms, and ultimately to timely referrals to the appropriate provider (community clinic, district clinic, or hospital) with electronic data transmitted to the health care delivery facility.

\section{CONCLUSION}

To date, most attention around $\mathrm{OH}$ has focused on policy and academic problem-solving. Academic groups, government agencies, and NGOs can, and should, meet and engage in strategic planning around the resolution of complex global $\mathrm{OH}$ problems requiring inter-disciplinary expertise, cooperation, and creative problem-solving. However, practically, a $\mathrm{OH}$ approach needs to start at the community level where there is a strong need for $\mathrm{OH}$ data collection and health information dissemination. Our innovative $\mathrm{OH}$ approach has the potential to bring a new trained workforce equipped with mHealth technology to rural communities to improve the health of people, animals, plants, and the environment. Furthermore, the benefits of a $\mathrm{OH}$ workforce are vital for surveillance of emerging diseases and chronic health problems across all siloes. By the systematic collection of data, and the daily compilation of that data using geo-tagged mapping there is the potential to improve disease surveillance and detection, decrease lag time in response, and enhance monitoring of outcomes. Given the interconnectedness of our global community in which humans, animals, plants, and the environment impact each other and do not respect geopolitical boundaries, we believe it is time for countries to consider training a communitybased $\mathrm{OH}$ workforce.

\section{ACKNOWLEDGEMENTS}

None.

FUNDING

Philippine Government (PCARI) IIHTM 16.

\section{COMPETING INTERESTS}

The authors have completed the Unified Competing Interest form at http://www.icmje.org/coi disclosure.pdf (available upon request from the corresponding author), and declare no conflicts of interest.

\section{CORRESPONDENCE TO:}

Michael Wilkes, MD, PhD

School of Medicine, University of California, Davis

1 Shield Ave, Davis, CA 95616

USA

mwilkes@ucdavis.edu 


\section{REFERENCES}

1. Daszak P, Berger L, Cunningham AA, Hyatt AD, Green DE, Speare R. Emerging infectious diseases and amphibian population declines. Emerg Infect Dis. 1999;5(6):735-748. doi:10.3201/eid0506.990601

2. Chakraborty S, Tiedemann AV, Teng PS. Climate change: potential impact on plant diseases. Environ Pollut. 2000;108(3):317-326. doi:10.1016/s0269-749 1(99)00210-9

3. Filipe JAN, Cobb RC, Meentemeyer RK, et al. Landscape epidemiology and control of pathogens with cryptic and long-distance dispersal: sudden oak death in northern Californian forests. Smith DL, ed. PLoS Comput Biol. 2012;8(1):e1002328. doi:10.1371/jo urnal.pcbi.1002328

4. Gatherer D. The 2014 Ebola virus disease outbreak in West Africa. J Gen Virol. 2014;95(8):1619-1624. do i:10.1099/vir.0.067199-0

5. Lanciotti RS. Origin of the West Nile virus responsible for an outbreak of encephalitis in the northeastern United States. Science. 1999;286(5448):2333-2337. doi:10.1126/science.286.5 $\underline{448.2333}$

6. Weaver SC, Reisen WK. Present and future arboviral threats. Antiviral Res. 2010;85(2):328-345. ㄸ oi:10.1016/j.antiviral.2009.10.008

7. Wolfe ND, Dunavan CP, Diamond J. Origins of major human infectious diseases. Nature. 2007;447(7142):279-283. doi:10.1038/nature05775

8. Mazet JAK, Clifford DL, Coppolillo PB, Deolalikar $A B$, Erickson JD, Kazwala RR. A “one health" approach to address emerging zoonoses: the HALI project in Tanzania. PLoS Med. 2009;6(12):e1000190. doi:10.1371/journal.pmed.1000190

9. Palacios G, Lowenstine LJ, Cranfield MR, et al. Human metapneumovirus infection in wild mountain gorillas, Rwanda. Emerg Infect Dis. 2011;17(4):711-713. doi:10.3201/eid1704.100883

10. Singh J, Kalamdhad AS. Effects of Heavy Metals on Soil, Plants, Human Health and Aquatic Life. Int J Res Chem Environ. 2011;1:15-21.

11. Environmental Protection Agency (EPA). Health and Ecological Hazards Caused by Hazardous Substances. Published January 2017. Accessed September 10, 2018. https://www.epa.gov/emergenc y-response/health-and-ecological-hazards-caused-ha zardous-substances
12. Reid WV HAM, Cropper A, Capistrano d, Carpenter SR, Chopra K, Dasgupta P, et al. Ecosystems and Human Well-being Synthesis. A Report of the Millennium Ecosystem Assessment. Published online 2005.

13. Machalaba C, Smith KM, Awada L, et al. One Health Economics to confront disease threats. Trans $R$ Soc Trop Med Hyg. 2017;111(6):235-237. doi:10.109 3/trstmh/trx039

14. Machalaba CC, Daszak P, Karesh WB, Shrivastava P. Future Earth and EcoHealth: A New Paradigm Toward Global Sustainability and Health. EcoHealth. 2015;12(4):553-554. doi:10.1007/s10393-015-1076-6

15. Schar DL, Yamey GM, Machalaba CC, Karesh WB. A framework for stimulating economic investments to prevent emerging diseases. Bull World Health Organ. 2018;96(2):138-140. doi:10.2471/blt.17.199547

16. World Bank Group. People, Pathogens and Our Planet: The Economics of One Health. World Bank Group; 2012. Accessed September 10, 2018. http://doc uments.worldbank.org/curated/en/6123414681478565 29/People-pathogens-and-our-planet-the-economic s-of-one-health

17. Lee Y, Kim H. The turning point of China's rural public health during the Cultural Revolution Period: Barefoot Doctors: A Narrative. Iran J Public Health. 2018;1:1-8.

18. Ryan TM. Trends in the supply of medical personnel in the Russian Federation. JAMA. 1996;276(4):339. doi:10.1001/jama.1996.03540040083 $\underline{045}$

19. The Lancet Global Health Editor. Community health workers: Emerging from the shadows? Accessed September 10, 2018. http://www.hifaorg/dgr oups-rss/lancet-global-health-community-health-wo rkers-emerging-shadows 2017

20. Food and Agriculture Organization (FAO). The FAO Action Plan on Antimicrobial Resistance 2016-2020. Contract No.: ISBN 978-92-5-109392-4. FAO; 2016.

21. Rodriguez P. Restoring Animal Health In Afghanistan: David Sherman, DVM. Veterinary Practice News. 2009.

22. Swanson B. Global Review of Good Agricultural Extension and Advisory Service Practices. Food and Agriculture Organization of the United Nations; 2008:82. 
23. Onwueme IC, Sinha TD. Field Crop Production in Tropical Africa. CTA Technical Publications; 1991.

24. World Health Organization (WHO). Emerging Issues in Water and Infectious Disease France: 2003. Accessed September 10, 2018. https://www.who.int/w ater_sanitation_health/publications/emergingissues/e $\underline{\mathrm{n} /}$

25. Brownstein JN, Chowdhury FM, Norris SL, et al. Effectiveness of community health workers in the care of people with hypertension. Am J Prev Med. 2007;32(5):435-447. doi:10.1016/j.amepre.2007.01.01 1

26. He J, Irazola V, Mills KT, et al. Effect of a community health worker-led multicomponent intervention on blood pressure control in low-income patients in Argentina: A randomized clinical trial. JAMA. 2017;318(11):1016. doi:10.1001/jama.2017.113 $\underline{58}$

27. Chong WTKM. minimum standards and guidelines for training of community-based animal health workers in Kenya. Kenya veterinary board.

28. World Health Organization (WHO) \& World Bank. New report shows that 400 million do not have access to essential health services. WHO and World Bank. Published online 2015. Accessed September 10, 2018. http://www.who.int/mediacentre/news/releases/2015/ uhc-report/en/

29. Bugeza J, Kankya C, Muleme J, et al. Participatory evaluation of delivery of animal health care services by community animal health workers in Karamoja region of Uganda. Jadhao SB, ed. PLoS ONE. 2017;12(6):e0179110. doi:10.1371/journal.pone.0179 110

30. Mockshell J, Ilukor J, Birner R. Providing animal health services to the poor in Northern Ghana: rethinking the role of community animal health workers? Trop Anim Health Prod. 2014;46(2):475-480. doi:10.1007/s11250-013-0518-9

31. Mutambara J, Dube I, Matangi E, Majeke F. Factors influencing the demand of the service of community based animal health care in Zimbabwe. Prev Vet Med. 2013;112(3-4):174-182. doi:10.1016/j.pr evetmed.2013.07.007
32. Braun R, Lasway C, Agarwal S, et al. An evaluation of a family planning mobile job aid for community health workers in Tanzania. Contraception. 2016;94(1):27-33. doi:10.1016/j.contraception.2016.0 $\underline{3.016}$

33. Karimuribo ED, Mutagahywa E, Sindato C, et al. A Smartphone App (AfyaData) for Innovative One Health Disease Surveillance from Community to National Levels in Africa: Intervention in Disease Surveillance. JMIR Public Health Surveill. 2017;3(4):e94. doi:10.2196/publichealth.7373

34. Trading Economics. Philippines - Rural population. Published 2017. Accessed January 22, 2019. https://tradingeconomics.com/philippines/rura 1-population-percent-of-total-population-wb-data.ht $\underline{\mathrm{ml}}$

35. Friel S, Marmot MG. Action on the social determinants of health and health inequities goes global. Annu Rev Public Health. 2011;32(1):225-236. d oi:10.1146/annurev-publhealth-031210-101220

36. World Bank. Current health expenditure (\% of GDP). Published online 2019. Accessed April 17, 2019. https://data.worldbank.org/indicator/SH.XPD.CHEX.G D.ZS?locations $=\mathrm{PH}$

37. Chongsuvivatwong V, Phua KH, Yap MT, et al. Health and health-care systems in southeast Asia: diversity and transitions. Lancet. 2011;377(9763):429-437. doi:10.1016/s0140-6736(1 0)61507-3

38. Dagangon L, Tupas M. Training needs analysis of Barangay Health Workers of Davao City. http://www.r esearchuiceduph/ojs/indexphpuicpi/article/view/5552 016

39. Nyatanyi T, Wilkes $\mathrm{M}$, McDermott $\mathrm{H}$, et al. Implementing One Health as an integrated approach to health in Rwanda. BMJ Glob Health. 2017;2(1):e000121. doi:10.1136/bmigh-2016-000121

40. World Bank. Employment in agriculture. Published online 2018. Accessed January 22, 2019. htt ps://data.worldbank.org/indicator/sl.agr.empl.zs 